Provided for non-commercial research and education use. Not for reproduction, distribution or commercial use.

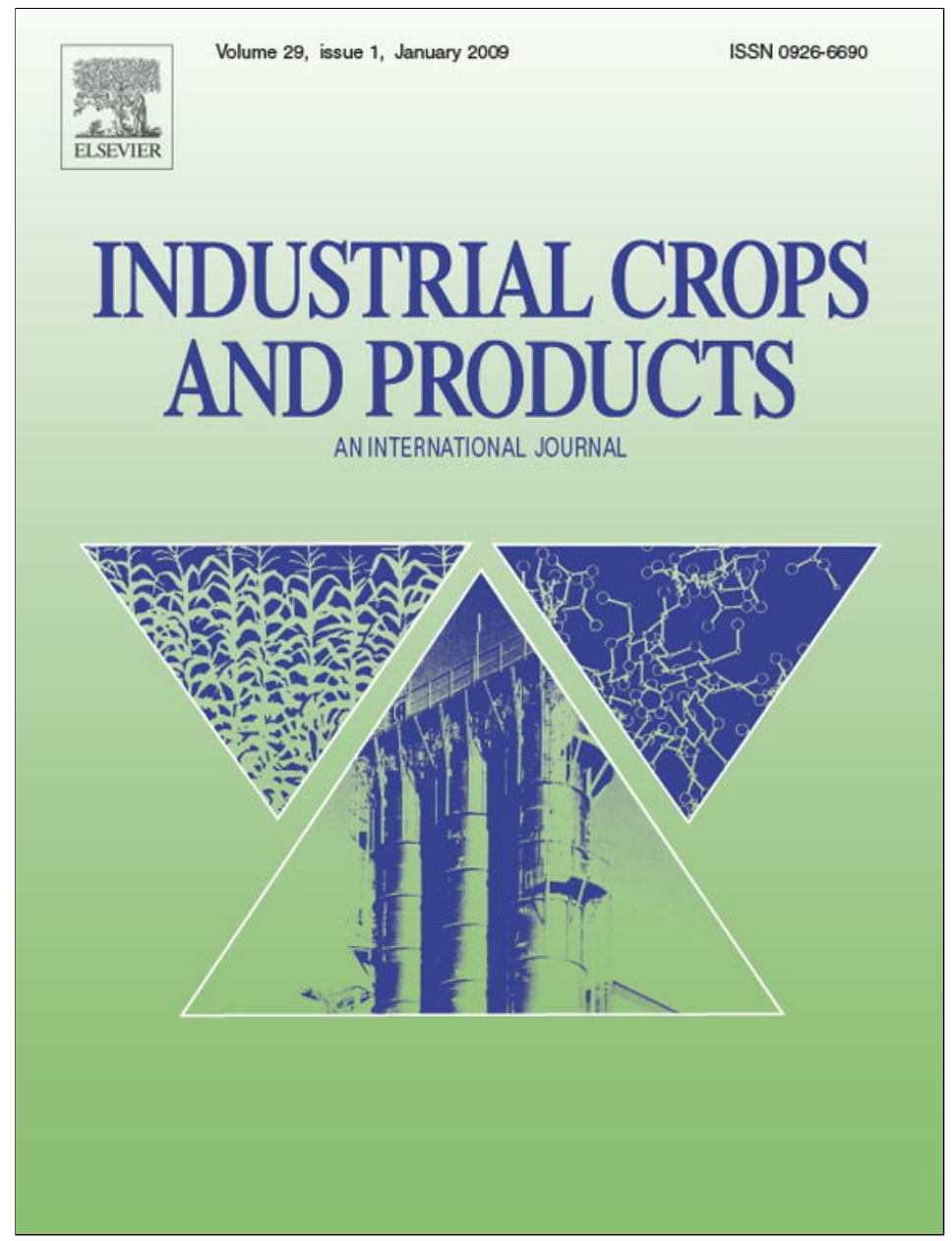

This article appeared in a journal published by Elsevier. The attached copy is furnished to the author for internal non-commercial research and education use, including for instruction at the authors institution and sharing with colleagues.

Other uses, including reproduction and distribution, or selling or licensing copies, or posting to personal, institutional or third party websites are prohibited.

In most cases authors are permitted to post their version of the article (e.g. in Word or Tex form) to their personal website or institutional repository. Authors requiring further information regarding Elsevier's archiving and manuscript policies are encouraged to visit:

http://www.elsevier.com/copyright 


\title{
Quercus suber and Betula pendula outer barks as renewable sources of oleochemicals: A comparative study
}

\author{
Paula C.R.O. Pinto ${ }^{a}$, Andreia F. Sousa $^{a}$, Armando J.D. Silvestre ${ }^{a, *}$, Carlos Pascoal Neto ${ }^{a}$, \\ Alessandro Gandini ${ }^{a}$, Christer Eckerman ${ }^{b}$, Bjarne Holmbom ${ }^{b}$ \\ a CICECO and Department of Chemistry, University of Aveiro, Campus de Santiago, 3810-193 Aveiro, Portugal \\ b Process Chemistry Centre, Laboratory of Wood and Paper Chemistry, Åbo Akademi University, FI-20500 Turku/Åbo, Finland
}

\section{A R T I C L E I N F O}

\section{Article history:}

Received 16 February 2008

Received in revised form

19 April 2008

Accepted 22 April 2008

\section{Keywords:}

Cork oak

Quercus suber L.

Cork

Birch

Betula pendula L.

Suberin

Chemical composition

$\omega$-Hydroxyfatty acids

$\alpha, \omega$-Dicarboxylic acids

\begin{abstract}
A B S T R A C T
A comparative study on the chemical composition of oak cork (Quercus suber L.) and corresponding industrial residues and birch (Betula pendula L.) outer bark is reported. Cork oak samples have lower extractives contents (6-9\%) and higher contents of carbohydrates and lignin (23-27 and 33-38\%, respectively) than those found for birch outer bark (40, 6 and $9 \%$, respectively); suberin contents accounted for around $30 \%$ of cork, $11 \%$ of industrial cork powder and $45 \%$ of birch outer bark. Analysis of the suberin monomeric composition revealed that C18 and C22 $\omega$-hydroxyfatty acids (including mid-chain epoxyand dihydroxy-derivatives), followed by $\alpha, \omega$-dicarboxylic acids, are the main components in both suberins, with 9,10-epoxy-18-hydroxyoctadecanoic, 18-hydroxyoctadec-9-enoic, 9,10,18-trihydroxyoctadecanoic and octadec-9-enoic acids as the major components. The differences in the relative amounts of these acids in the suberin samples and the impact on the potential exploitation of the different industrial by-products are discussed.
\end{abstract}

(c) 2008 Elsevier B.V. All rights reserved.

\section{Introduction}

The foreseeable gradual depletion of fossil resources and the need for sustainable development of world's industrial production systems are driving both the scientific community and industry to look for alternative and renewable resources for production of energy, materials and chemical commodities. Biomass emerges in this context as the logical raw material for the sustainable production of chemicals. In fact, from the estimated $1.7 \times 10^{11}$ ton of biomass produced annually by pho- tosynthesis, only $6 \times 10^{9}$ ton are used, and only $3 \%$ of this in non-food applications (Kamm and Kamm, 2004; Kamm et al., 2006). The production of chemicals from biomass in this new venture will be carried out in the so-called biorefineries, which will transform multiple biomass feedstocks, to produce a portfolio of products, including fuels, energy, chemicals and materials (Kamm and Kamm, 2004; Kamm et al., 2006). Among these biorefineries of the future, the lignocellulosic feedstock (LCF) biorefineries, will probably be the most successful, on the one hand, because of the availability of feedstocks (both ded-

This publication reflects only the authors views, and the European Commission is not liable for any use that may be made from the information contained herein.

* Corresponding author. Tel.: +351 234370 711; fax: +351 234370084 .

E-mail address: armsil@ua.pt (A.J.D. Silvestre).

0926-6690/\$ - see front matter @ 2008 Elsevier B.V. All rights reserved.

doi:10.1016/j.indcrop.2008.04.015 
icated crops, and agro-food wastes, or even paper wastes) at competitive prices and, on the other hand, because they do not compete with the supply of food (Fernando et al., 2006). The implementation of the biorefinery concepts in already existing agroforest-based activities and the concomitant need to upgrade the by-products generated in the processing of agricultural and forest products, represent a short-term response to this goal (Kamm et al., 2006). In this context, the processing of oak cork, and pulping of birch are well established industrial activities that generate considerable amounts of cork and outer bark residues, which for the time being are under-exploited and could have considerable value as sources of oleochemicals.

The outer bark of Quercus suber is commonly known as cork (hereafter designated as such). Cork production and its processing industry (mainly for the production of cork stoppers and thermal and/or acoustic insulation materials) exist mainly in the Mediterranean region (Silva et al., 2005). In Portugal, about 185,000 ton/year of cork are produced, representing more than $50 \%$ of the world production (APCOR, 2008). This industry generates substantial amounts of the so-called "cork powder", representing about 40,000 ton/year in Portugal (Gil, 1988), that is not suitable for current industrial uses. This byproduct is currently burned to produce energy.

Birch (Betula pendula) is an important species for pulp production in the Nordic countries. Birch logs contain about 3.4\% outer bark (Jensen, 1948). Thus, a birch kraft pulp mill, with an annual pulp production of 400,000 ton/year generates about 28,000 ton of outer bark (Ekman, 1983), which is, at the present, burnt in the biomass boilers of kraft pulp mills for energy production. Based on birch kraft pulp production figures, the total potential of birch outer bark in Finland can be estimated to be 200,000 ton/year (Paper and wood insights, 2006). These two bark by-products bear in common the fact that their main constituent is suberin. Suberin is an aromatic-aliphatic crosslinked polyester. It is widespread in the plant kingdom, where it plays a key role as a protective barrier between the plant and the surrounding environment. It is found mainly in the cell walls of normal and wounded external tissues of aerial and/or subterranean parts of many plants, mainly in the outer bark of higher plants and in tuber periderms (Bernards, 2002). However, only the two species considered in the present paper produce suberin-rich biomass residues in amounts that can justify their exploitation as renewable sources of chemicals.

Suberin is of interest mainly because it constitutes an abundant source of $\omega$-hydroxyfatty acids, $\alpha, \omega$-dicarboxylic acids and homologous mid-chain dihydroxy or epoxy derivatives (Gandini et al., 2006) that, apart from these sources, are not abundant in nature. In fact, hydroxyfatty acids can only additionally be found in exploitable amounts in the seed oils of Ricinus communis (castor oil) and Lesquerella spp., as well as in the extra-cellular aliphatic polyester covering most of the aerial surfaces of plants, known as cutin (Christie, 2008).

The most interesting applications for suberin components that are being investigated involves their use in the synthesis of polymeric materials (Gandini et al., 2006), notably polyols through oxypropylation (Evtiouguina et al., 2000, 2002), polyurethanes synthesis, either from the oxypropylated material (Evtiouguina et al., 2001) or from depolymerized suberin mixtures (Cordeiro et al., 1997, 1999), and finally polyesters, either from depolymerized suberin mixtures (Sousa et al., 2007) or from isolated monomers (Olsson et al., 2007).

The efficient isolation and exploitation of the suberin fractions of cork powder or birch outer bark requires a detailed knowledge of the chemical composition of each substrate, and of the suberin depolymerization mixtures in particular. Cork is mainly composed of lignin ( $25 \%)$, polysaccharides ( $20 \%)$, suberin ( 40\%), extractives ( $15 \%$ ) and minor amounts of inorganic salts $(\sim 1 \%)$. These figures are, however, much variable, being influenced by the geographical origin and quality of the tree, and/or even the different parts of the tree from which the cork is harvested (Pereira, 1988; Conde et al., 1998, 1999). Birch outer bark has a high content of extractives, varying between 20 and $45 \%$. The suberin content, if calculated on extractive-free outer bark, is fairly constant with an average of about $50 \%$ by weight (Ekman, 1983). Suberin is easily depolymerized under alkaline hydrolysis/alcoholysis conditions; the chemical composition of the ensuing suberin depolymerization mixtures (as well as its relationship with the structure of the native biopolymer) has been the object of a large number of publications which have been extensively reviewed in recent years (Bernards, 2002; Gandini et al., 2006). Although these depolymerization mixtures are mainly composed of $\omega$ hydroxyfatty acids, $\alpha, \omega$-dicarboxylic acids and homologous mid-chain dihydroxy or epoxy derivatives, the relative abundance of these components is, on one hand, dependent on the nature of the biomass source, as mentioned above and, on the other hand, on the depolymerization and extraction conditions (Bernards, 2002; Gandini et al., 2006).

Within the scope of an European research project aiming to develop new concepts for the upgrading of pulp and cork mill waste streams to value-added chemicals, one of the main goals is the valorization of industrial cork powder (ICP) and birch outer bark, particularly through the use of suberin components as a renewable source of monomers for the synthesis of polymeric materials. In this context, a detailed knowledge of the chemical composition of the two bark by-products is required, particularly in what concerns the depolymerized suberin mixtures. The present paper reports the results of the overall characterization of birch outer bark, cork and industrial cork powder and the detailed characterization of depolymerized suberin obtained by mild alkaline hydrolysis or alkaline methanolysis. The suberin depolymerization products are in this paper designated as "dep-suberin". Mild alkaline hydrolysis conditions yield dep-suberin components as free acids, and preserves epoxide-containing structures (Ekman and Eckerman, 1985). Alkaline methanolysis yields dep-suberin components as methyl esters and the epoxy-containing structures are largely converted to the corresponding methoxyhydrin structures (Gandini et al., 2006).

\section{Experimental}

\subsection{Samples}

Quercus suber L. cork (QsC) planks, "Amadia” grade, were sampled in the south part of Portugal (Herdade da Moinhola, Amorim Florestal mill, Portugal, March 2005). The ICP was sampled in the Corticeira Amorim mill (Portugal, February 
2005). Cork was ground in a Retsch SK hammer mill, sieved, and the 40-60 mesh fraction was used for further analyses. ICP was sieved to 40-60 mesh and used as such.

Betula pendula outer bark samples (BoB) were collected from the debarking line at a birch kraft pulp mill in Finland (Metsä-Botnia, Kaskinen). The industrial bark was ground in a laboratory mill to pass a 6-mm screen, followed by separation in water into floating outer bark and sedimented inner bark. The outer bark was air dried and sieved to 40-60 mesh. Ash contents were quantified following TAPPI T 221 om-93.

\subsection{Isolation of extractives}

BoB extractives were fully removed by Soxhlet extraction with ethanol during $20 \mathrm{~h}$, whereas QsC and ICP were sequentially Soxhlet-extracted with dichloromethane, methanol and water during $10 \mathrm{~h}$ for each solvent. The extracts were dried to constant weight and quantified gravimetrically.

All preparative procedures described from this point onwards were carried out in duplicate.

\subsection{Suberin depolymerization}

Extractive-free samples were submitted to two different depolymerization procedures: (i) alkaline hydrolysis (for all samples) and (ii) alkaline methanolysis (for QsC and ICP).

(i) Alkaline hydrolysis. Alkaline hydrolysis was carried out with a solution of $0.5 \mathrm{M} \mathrm{KOH}$ in ethanol/water $(9: 1, \mathrm{v} / \mathrm{v})$ at $70{ }^{\circ} \mathrm{C}$ for $1.5 \mathrm{~h}$ (Ekman and Eckerman, 1985). The mixture of hydrolyzed suberin monomers was cooled to room temperature and acidified with dilute sulfuric acid to about pH 3-3.5, and extracted three times with methyl t-butyl ether (MTBE). The solvent was then removed in a rotary evaporator and the residue weighed.

(ii) Alkaline methanolysis. Cork samples (QsC, ICP) were refluxed with a dried methanol solution of $0.6 \mathrm{M} \mathrm{NaOCH}_{3}$ during $4 \mathrm{~h}$, followed by solid residue filtration, and $1 \mathrm{~h}$ reflux with methanol (Lopes et al., 2000). The combined liquid fractions were mixed, acidified to about $\mathrm{pH}$ 3-3.5 with diluted $\mathrm{H}_{2} \mathrm{SO}_{4}$, and then extracted three times with dichloromethane. The solvent was then removed in a rotary evaporator and the residue weighed.

\subsection{Klason lignin}

Acid-insoluble (Klason) lignin of the solid residue (obtained after suberin extraction) was quantified as described elsewhere (Browning, 1967).

\subsection{Analysis of carbohydrates}

Neutral monosaccharides were released from the solid residue (obtained after suberin extraction) by treatment with $72 \%$ $\mathrm{H}_{2} \mathrm{SO}_{4}$ at $25^{\circ} \mathrm{C}$, followed by hydrolysis with $1 \mathrm{M} \mathrm{H}_{2} \mathrm{SO}_{4}$ at $100^{\circ} \mathrm{C}$ (Saemen hydrolysis) as described elsewhere (Coimbra et al., 1996) and quantified as alditol acetate derivatives by GC (Selvendran et al., 1979).

The same residues were also submitted to acid methanolysis with $2 \mathrm{M} \mathrm{HCl}$ in anhydrous methanol. After $5 \mathrm{~h}$ at $100^{\circ} \mathrm{C}$, the samples were neutralised with pyridine, and sorbitol was added as internal standard. The sample was transferred to a new flask, dried and converted into TMS as reported elsewhere (Sundberg et al., 1996).

\subsection{Chromatographic analysis}

Dep-suberins were converted to TMS derivatives according to a known procedure (Ekman, 1983). Derivatized cork depsuberin samples were analyzed by GC-MS using a Trace GC 2000 gas chromatograph, connected to a mass selective detector Finnigan Trace MS, and previously described chromatographic conditions (Lopes et al., 2000). For quantitative analysis, GC-MS was calibrated with pure reference compounds representative of the major classes of components present in cork, relative to the $n$-tetracosane, the internal standard used. Identification of chromatographic peaks is based on the equipments spectral library (Wiley-Nist), and also on comparison with previously published data (Cordeiro et al., 1998; Ekman, 1983; Ekman and Eckerman, 1985; Lopes et al., 2000; and references therein).

Derivatized birch outer bark dep-suberin samples were analysed on a Hewlett Packard model 5973 GC/MSD system following previously described chromatographic conditions (Ekman and Eckerman, 1985) and identified as referred to above, while quantitative analyses were performed on a PerkinElmer Autosystem XL GC.

The monosaccharide alditol acetates were analyzed by GC using a Varian 3350 GC, following previously described chromatographic conditions (Pinto et al., 2005). Monosaccharides from acid methanolysis were analysed by GC as described elsewhere (Sundberg et al., 1996).

All quantitative analysis were performed at least in triplicate and accepted when the variability between analyses was lower than 5\%. Quantitative results presented are the average of the triplicate analysis of the duplicate samples.

\section{Results and discussion}

\subsection{Overall chemical composition}

The overall composition of the studied samples is shown in Table 1. The yields of dep-suberin obtained by hydrolysis of BoB and QsC (45 and 29\%, respectively) are within the ranges reported in the literature (Gandini et al., 2006). How-

\begin{tabular}{|c|c|c|c|}
\hline Component & BoB & QsC & ICP \\
\hline Extractives & 40 & 9 & 6 \\
\hline Ash & 1 & 4 & 6 \\
\hline Klason lignin & 9 & 33 & 38 \\
\hline Carbohydrates & 6 & 23 & 27 \\
\hline \multicolumn{4}{|l|}{ Dep-suberin } \\
\hline Alkaline hydrolysis & 45 & 29 & 11 \\
\hline Alkaline methanolysis & - & 33 & 11 \\
\hline
\end{tabular}


ever, for QsC, the reported value is at the lower limit of the mentioned ranges. ICP yielded considerably lower amounts of dep-suberin (11\%) when compared to the native cork (QsC).

The three samples also gave considerably different yields for the other components: while BoB had a high content of extractives (40\%) and low contents of other macromolecular components (9\% of Klason lignin and $6 \%$ of polysaccharides), QsC and ICP had lower contents of extractives (9 and 6\%, respectively) and higher amounts of Klason lignin (33 and 38\%, respectively) and carbohydrates (23 and $27 \%$, respectively). The Klason lignin content of QsC was high when compared to published results for natural cork (Pereira, 1988; Marques et al., 1994).

The extractives content of QsC are within the typical values found for mature ("Amadia" grade) cork (Pereira, 1988; Lopes et al., 2000). The major components of the dichloromethane and methanol extracts of QSC and ICP were triterpenoid components (10.3 and $17.1 \mathrm{~g} / \mathrm{kg}$, respectively), with cerine and friedeline as the major components in QsC and betulinic acid in ICP extracts, as recently reported in detail (Sousa et al., 2006). The ethanol extract of BoB was also mainly composed of triterpenoids, with betulinol representing about $80 \%$ of the total.

The total carbohydrates as monomeric sugars were obtained by acid hydrolysis. The sugars of non-cellulosic carbohydrates were obtained by acid methanolysis. From these results, the cellulose content was calculated as the total amount of glucose by acid hydrolysis with subtraction of glucose from acid methanolysis (Table 2). The non-cellulosic carbohydrates, most probably originating mainly from hemicelluloses, were calculated as the total sum of sugars from acid methanolysis.

The cork samples contained considerable amounts of cellulose, whereas BoB contained a very small amount (Table 2). The same is also true for non-cellulosic carbohydrates. The non-cellulosic carbohydrates of BoB were dominated by arabinose, followed by xylose and several other sugars in smaller amounts (Table 3). The high amount of arabinose indicates the presence of arabinans as predominant hemicelluloses. This topic needs further research since there are no reports in the literature about birch outer bark hemicelluloses composition and structure.

Xylose was the dominating non-cellulosic sugar in both cork samples, indicating the presence of xylans, as previously suggested (Asensio, 1987a,b). This is supported also by the presence of 4-O-methyl glucuronic acid units. However, the complex composition of the neutral and acidic non-cellulosic carbohydrates indicates also the existence of other types of hemicelluloses in cork. This topic in now under investigation.

Table 2 - Cellulose and non-cellulosic carbohydrates, in wt.\% of whole samples

\begin{tabular}{llll} 
Component & BoB & QsC & ICP \\
\hline Cellulose & 1.8 & 12.1 & 11.4 \\
Non-cellulosic carbohydrates & 4.2 & 11.2 & 15.6 \\
Total carbohydrates & 6.0 & 23.3 & 27.0 \\
\hline
\end{tabular}

Table 3 - Monosaccharide composition of non-cellulosic carbohydrates (by acid methanolysis and GC), \% of pre-extracted samples, with \% composition in parenthesis

\begin{tabular}{llll} 
Component & \multicolumn{1}{c}{ BoB } & \multicolumn{1}{c}{ QsC } & \multicolumn{1}{c}{ ICP } \\
\hline Arabinose & $2.7(46)$ & $2.0(16)$ & $1.9(12)$ \\
Xylose & $0.9(15)$ & $5.3(43)$ & $8.6(52)$ \\
4-O-Methyl glucuronic acid & $0.1(2)$ & $0.6(5)$ & $1.0(6)$ \\
Rhamnose & $0.2(3)$ & $0.5(4)$ & $0.7(4)$ \\
Galacturonic acid & $0.7(12)$ & $1.6(13)$ & $1.2(7)$ \\
Galactose & $0.8(14)$ & $1.1(9)$ & $1.9(12)$ \\
Glucose & $0.3(5)$ & $0.7(6)$ & $0.8(5)$ \\
Mannose & $0.2(3)$ & $0.4(3)$ & $0.4(2)$ \\
Total & $5.9(100)$ & $12.2(100)$ & $16.5(100)$ \\
\hline
\end{tabular}

The predominance of extractives and the low abundance of lignin and carbohydrates in BoB, when compared to QsC and ICP, is an important aspect in by-products processing to obtain dep-suberin fractions. After extractives removal, BoB residues will be considerably enriched in suberin and, upon alkaline hydrolysis/alcoholysis, the ensuing mixtures will be particularly enriched in suberin monomeric units; whereas in the case of QSC and particularly in ICP, the alkaline hydrolysis/alcoholysis mixtures may be more contaminated with lignin and polysaccharides residues.

There are considerable differences in the chemical composition of QSC and ICP. ICP has a higher content of lignin, with smaller amounts of suberin, which is certainly related with the enrichement of ICP in the inner and outer surface fractions of cork planks, rejected during cork stopper manufacture. Particularly the outer surface (the major fraction of ICP) should be more lignified than the "bulk", and certainly enriched in complex mixtures of photodegraded extractives, polysaccharides, lignin and suberin, due to environmental exposure. Finally, the fact that only about $90 \%$ of the mass of ICP was accounted for should also be related to the particular nature of this fraction and the remaining $10 \%$ should be water-soluble polar organic compounds released during the alkaline hydrolysis.

\subsection{Dep-suberin chemical composition}

The chemical composition of dep-suberin fractions from BoB, QsC and ICP obtained under different depolymerization conditions is shown in Table 4. The GC-MS analyses of dep-suberin samples from alkaline hydrolysis show that, for all substrates, only part of the dep-suberin isolated by solvent extraction (Table 2) corresponds to suberin monomeric components (60, 37 and 36\%, respectively, for BoB, QsC and IcP), although, in the case of QSC and ICP a small percentage (less than 6\%) of other suberin related components, not shown in Table 4 , were also detected. The high percentage of undetected components means that a non-volatile fraction, not detectable by GC-MS, is present in these dep-suberin extracts; this observation is in agreement with previously reported results for Quercus suber cork (Lopes et al., 2000; Gandini et al., 2006). A tentative explanation is that this fraction should be composed by suberan-type high molecular-mass aliphatic moieties, nondetectable by GC-MS (Tegelaar et al., 1995). 
Table 4 - Main dep-suberin monomers of ICP, BoB and QsC isolated by alkaline hydrolysis and methanolysis identified by GC-MS expressed in $\mathrm{mg}$ compound/g of dry starting material or $\mathrm{mg}$ compound/g of extracted suberin (in parenthesis)

\begin{tabular}{|c|c|c|c|c|c|}
\hline & \multicolumn{3}{|c|}{ Hydrolysis } & \multicolumn{2}{|c|}{ Methanolysis } \\
\hline & $\mathrm{BoB}^{\mathrm{a}}$ & $\mathrm{QsC}^{\mathrm{a}}$ & $\mathrm{ICP}^{\mathrm{a}}$ & $\mathrm{QsC}^{\mathrm{a}}$ & $\mathrm{ICP}^{\mathrm{a}}$ \\
\hline Hexadecanedioic acid & $1(2)$ & $3(10)$ & $1(9)$ & $\operatorname{Tr}$ & $\operatorname{tr}$ \\
\hline Octadecanedioic acid & $2(2)$ & $1(3)$ & $\operatorname{tr}$ & $\operatorname{Tr}$ & $\operatorname{tr}$ \\
\hline Octadec-9-enedioic acid & $13(29)$ & $8(28)$ & $3(27)$ & $\operatorname{Tr}$ & $\operatorname{tr}$ \\
\hline Eicosanedioic acid & $4(9)$ & $1(3)$ & $\operatorname{tr}$ & $\operatorname{Tr}$ & $\operatorname{tr}$ \\
\hline Docosanedioic acid & $16(36)$ & $3(10)$ & $1(9)$ & $1(3)$ & $\operatorname{tr}$ \\
\hline Alkanedioic acids & $36(80)$ & $16(55)$ & $5(45)$ & $1(3)$ & 0 \\
\hline 16-Hydroxyhexadecanoic acid & $1(2)$ & $2(7)$ & $1(9)$ & $1(3)$ & $1(9)$ \\
\hline Dihydroxyhexadecanoic acid & $9(20)$ & $\operatorname{tr}$ & $\operatorname{tr}$ & $\operatorname{Tr}$ & $\operatorname{Tr}$ \\
\hline 18-Hydroxyoctadec-9-enoic acid & $39(87)$ & $23(79)$ & $8(73)$ & $6(18)$ & $4(36)$ \\
\hline 20-Hydroxyeicosanoic acid & $9(20)$ & $4(14)$ & $1(9)$ & $1(3)$ & $1(9)$ \\
\hline 20-Hydroxyeicos-10-enoic acid & $5(11)$ & $3(10)$ & $1(9)$ & $1(3)$ & $\operatorname{Tr}$ \\
\hline 22-Hydroxydocosanoic acid & $42(93)$ & $23(79)$ & $7(64)$ & $23(70)$ & $8(73)$ \\
\hline 24-Hydroxytetracosanoic acid & $1(2)$ & $4(14)$ & $2(18)$ & $3(9)$ & $2(18)$ \\
\hline Hydroxyalkanoic acids & $106(236)$ & $58(200)$ & $20(182)$ & $35(106)$ & $16(145)$ \\
\hline 9,10-Epoxy-18-hydroxyoctadecanoic acid & $99(220)$ & $14(48)$ & $4(36)$ & - & - \\
\hline 9,10-Epoxyoctadecanedioic acid & $\operatorname{tr}$ & $10(34)$ & $2(18)$ & - & - \\
\hline 9,10,18-Trihydroxyoctadecanoic acid & $29(64)$ & $5(17)$ & $3(27)$ & $3(9)$ & $2(18)$ \\
\hline 9,18-Dihydroxy-10-methoxyoctadecanoic acid & - & - & - & $5(15)$ & $2(18)$ \\
\hline 9,10-Dihydroxyoctadecanedioic acid & $\operatorname{tr}$ & $5(17)$ & $2(18)$ & - & - \\
\hline Epoxy derivatives & $128(284)$ & $34(117)$ & $14(127)$ & $8(24)$ & $4(36)$ \\
\hline Total & $270(600)$ & $108(372)$ & $39(355)$ & $44(133)$ & $20(182)$ \\
\hline
\end{tabular}

a Dep-suberin monomer.

The major groups of components found in the dep-suberin fractions (Table 4) are alkanedioic and $\omega$-hydroxyalkanoic acids and the corresponding epoxy-derivatives (typical chromatograms of both dep-suberin samples are shown in Fig. 1, while the structures of the most abundant identified compounds are shown in Fig. 2). In the case of cork, dep-suberin contained smaller amounts of fatty acids and alcohols (less than $2 \%$ in both subtrates), and ferulic acid (less than $4 \%$ ) were also detected, in accordance with previously reported results (Gandini et al., 2006). The relative abundance of individual components is largely different between birch and cork samples. For BoB, the most abundant component is 9,10 -epoxy-18-hydroxyoctadecanoic acid $(99 \mathrm{mg} / \mathrm{g})$, which accounts for about $37 \%$ of the identified components, followed by 22-hydroxydocosanoic $(42 \mathrm{mg} / \mathrm{g})$, 18-hydroxyoctadec-9enoic $(39 \mathrm{mg} / \mathrm{g})$ and 9,10,18-trihydroxyoctadecanoic acid

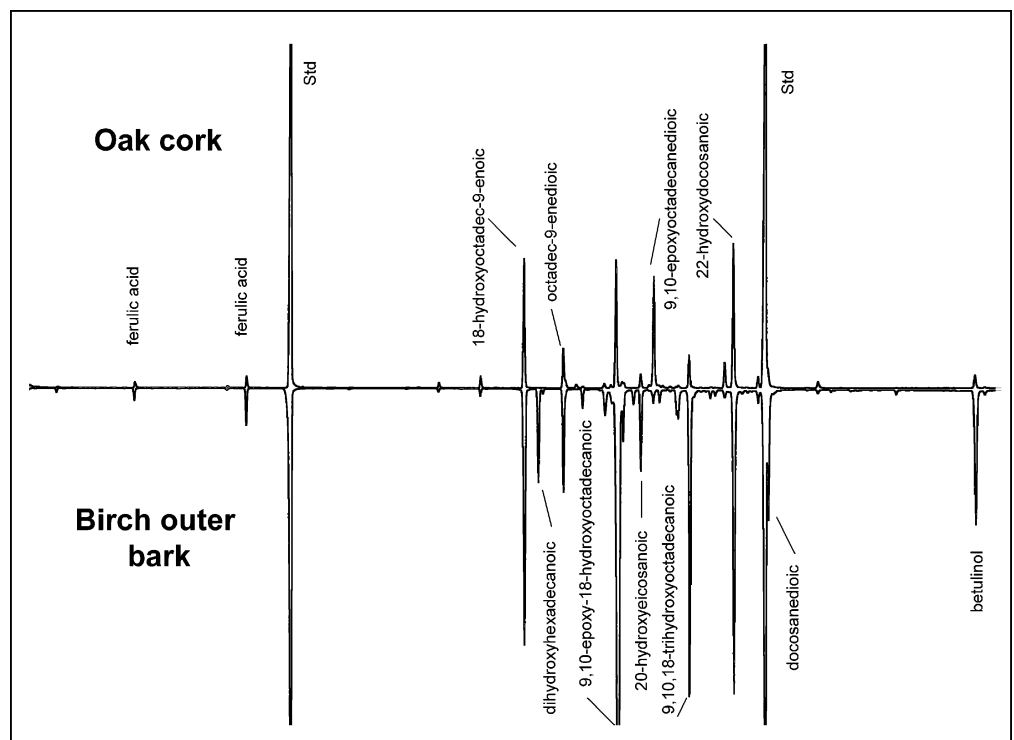

Fig. 1 - Comparison of depolymerized cork and birch outer bark suberin acid composition by GC-MS. 
Alkanedioic acids

Octadec-9-enedioic acid

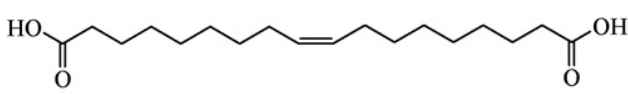

Docosanedioic acid

Hydroxyalkanoic acids

18-Hydroxyoctadec-9-enoic acid

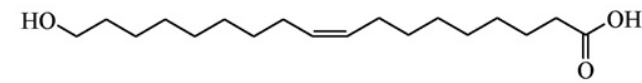

22-Hydroxydocosanoic acid

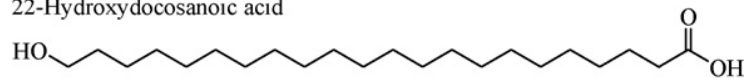

Epoxyde derivatives

9,10-epoxy-18-hydroxyoctadecanoic acid

$\overbrace{O}^{O H O}$

9,10,18-Trihydroxyoctadecanoic acid<smiles>O=C(O)CCCCCCCC(O)C(O)CCCCCCCCO</smiles>

$\mathrm{OH}$

Fig. 2 - Structures of the most abundant components identified in dep-suberin samples.

$(29 \mathrm{mg} / \mathrm{g})$, with this last component resulting from the cleavage of the corresponding epoxide. The most abundant alkanedioic acids found in BoB are docosanedioic and octadec9-enedioic acids (16 and $13 \mathrm{mg} / \mathrm{kg}$, respectively). The major components detected in dep-suberin of QsC and ICP were 22-hydroxydocosanoic (23 and $8 \mathrm{mg} / \mathrm{g}$, respectively) and 18hydroxyoctadec-9-enoic acids (23 and $7 \mathrm{mg} / \mathrm{g}$, respectively), followed by 9,10-epoxy-18-hydroxyoctadecanoic acid (14 and $4 \mathrm{mg} / \mathrm{g}$, respectively) and 9,10-epoxyoctadecanedioic acid (10 and $2 \mathrm{mg} / \mathrm{g}$, respectively). The low abundance of epoxy derivatives in both QsC and ICP hydrolysis dep-suberin samples is a key difference to $\mathrm{BoB}$, and confirms the low abundance of this type of structures in cork suberin.

Analysis of the QSC and ICP dep-suberins obtained by alkaline methanolysis showed a considerable decrease in the total amount of components detected when compared to the alkaline hydrolysis data. Although the amounts of 22hydroxydocosanoic acid detected $(23$ and $8 \mathrm{mg} / \mathrm{g}$ for QsC and ICP, respectively) are similar to those obtained by alkaline hydrolysis, much lower amounts of 18-hydroxyoctadec-9enoic acids ( 6 and $4 \mathrm{mg} / \mathrm{g}$, respectively) and the absence of epoxide-containing compounds is observed; cleavage products, namely 9,18-dihydroxy-10-methoxyoctadecanoic acid, were detected in small amounts (Table 4). Considering the decrease in the amounts of compounds detected by GC-MS in dep-suberin obtained by alkaline methanolysis, the above referred increase in the corresponding extraction yield means that a higher amount of non-volatile components was isolated under these conditions. However, taking into account that, under methanolysis conditions, 22-hydroxydocosanoic acid was clearly dominant and was obtained in the same amounts as from hydrolysis, the former can be a good approach for further processing of dep-suberin when the isolation of the pure compound is required.

\section{Conclusions}

The high content of extractives and low contents of polysaccharides and lignin of birch outer bark enable the isolation of less contaminated dep-suberin, compared to the one obtained under similar conditions from cork or cork byproducts, resulting in higher amounts of suberin monomeric units. Furthermore, the high content of 9,10-epoxy-18hydroxyoctadecanoic acid in BoB dep-suberin, might justify further processing of depolymerization mixtures in order to isolate the pure compound for more valuable applications such as polyester synthesis (Olsson et al., 2007). In the case of cork, the yields of dep-suberin isolation and the amounts of compounds are smaller than for birch, and there is not a dominant component (excepting for 22-hydroxydocosanoic acid in methanolysis dep-suberin) that could justify further working up of the extract to isolate it in a pure state. In this case, the exploitation of dep-suberin will certainly pass through the direct processing of the entire mixture, possibly after a purification step to separate suberin monomers from the undetected fraction.

The even lower amounts of monomers detected in the dep-suberin obtained by methanolysis suggests that this depolymerization pathway is of interest only if the monomers are required in methyl ester form (e.g., for polyester synthesis through transesterification), or for the isolation of 22hydroxydocosanoic acid, the dominant component detected in this fraction.

\section{Acknowledgements}

This work was carried out under project WaCheUp (contract number STRP 013896), European Community, Sixth Framework Programme, priority 3, NMP.

This work is part of the activities at the Åbo Akademi Process Chemistry Centre within the Finnish Centre of Excellence Programme by the Academy of Finland.

Amorim group is gratefully acknowledged for supplying cork and cork by-products samples; Metsä-Botnia, Kaskinen is gratefully acknowledged for supplying birch bark samples.

\section{REFERENCES}

APCOR, 2008. Associação Portuguesa da Cortiça. www. corkmasters.com (browsed in February 2008).

Asensio, A., 1987a. Quercus suber polysaccharides. 1. Structural studies of the hemicellulose-A from the cork of Quercus suber. Carbohydr. Res. 161 (1), 167-170.

Asensio, A., 1987b. Quercus suber polysaccharides. 2. Structural studies of a hemicellulose-B fraction from the cork of Quercus suber. Carbohydr. Res. 165 (1), 134-138.

Bernards, M.A., 2002. Demystifying suberin. Can. J. Bot. 80 (3), 227-240.

Browning, B.L., 1967. Methods in Wood Chemistry. Interscience Publishers, New York.

Christie, W.W., 2008. The lipid library. http://www.lipidlibrary. co.uk/ (browsed in February 2008).

Coimbra, M.A., Delgadillo, I., Waldron, K.W., Selvendran, R.R., 1996. Isolation and analysis of cell wall polymers from plive pulp. In: Linskens, H.F., Jackons, J.F. (Eds.), Modern Methods of 
Plant Analysis. Springer-Verlag, Berlin, pp. 19-44.

Conde, E., Cadahia, E., Garcia-Vallejo, M.C., Gonzalez-Adrados, J.R., 1998. Chemical characterization of reproduction cork from Spanish Quercus suber. J. Wood Chem. Technol. 18 (4), 447-469.

Conde, E., Garcia-Vallejo, M.C., Cadahia, E., 1999. Variability of suberin composition of reproduction cork from Quercus suber throughout industrial processing. Holzforschung 53 (1), 56-62.

Cordeiro, N., Belgacem, M.N., Gandini, A., Neto, C.P., 1997.

Urethanes and polyurethanes from suberin. 1. Kinetic study. Ind. Crops Prod. 6 (2), 163-167.

Cordeiro, N., Belgacem, M.N., Silvestre, A.J.D., Neto, C.P., Gandini, A., 1998. Cork suberin as a new source of chemicals. 1. Isolation and chemical characterisation of its composition. Int. J. Biol. Macromol. 22, 71-80.

Cordeiro, N., Belgacem, M.N., Gandini, A., Neto, C.P., 1999. Urethanes and polyurethanes from suberin. 2. Synthesis and characterization. Ind. Crops Prod. 10 (1), 1-10.

Ekman, R., 1983. The Suberin monomers and triterpenoids from the outer bark of Betula verrucosa Ehrh. Holzforschung 37 (4), 205-211.

Ekman, R., Eckerman, C., 1985. Aliphatic carboxylic acids from suberin in birch outer bark by hydrolysis, methanolysis, and alkali fusion. Paperi Ja Puu 67 (4), 255-273.

Evtiouguina, M., Barros, A.M., Cruz-Pinto, J.J., Neto, C.P., Belgacem, N., Pavier, C., Gandini, A., 2000. The oxypropylation of cork residues: preliminary results. Bioresource Technol. 73 (2), 187-189.

Evtiouguina, M., Gandini, A., Neto, C.P., Belgacem, N.M., 2001. Urethanes and polyurethanes based on oxypropylated cork. 1. Appraisal and reactivity of products. Polym. Int. 50 (10), 1150-1155.

Evtiouguina, M., Barros-Timmons, A., Cruz-Pinto, J.J., Neto, C.P., Belgacem, M.N., Gandini, A., 2002. Oxypropylation of cork and the use of the ensuing polyols in polyurethane formulations. Biomacromolecules 3 (1), 57-62.

Fernando, S., Adhikari, S., Chandrapal, C., Murali, N., 2006. Biorefineries: current status, challenges, and future direction. Energy Fuels 20 (4), 1727-1737.

Gandini, A., Neto, C.P., Silvestre, A.J.D., 2006. Suberin: a promising renewable resource for novel macromolecular materials. Progr. Polym. Sci. 31 (10), 878-892.

Gil, L., 1988. Cortiça, Produção Tecnologia e Aplicação. INETI, Lisbon.

Jensen, W., 1948. Om ytskiktsavfallet vid framställning av björkfaner (About the surface layer waste from production of birch veneer). Ph.D. Thesis. Acta Acad. Aboensis, Math. Phys. XVI, 3.
Kamm, B., Kamm, M., 2004. Principles of biorefineries. Appl. Microbiol. Biotechnol. 64 (2), 137-145.

Kamm, B., Gruber, P.R., Kamm, M., 2006. Biorefineries-Industrial Processes and Products. Wiley-VCH, Weinheim.

Lopes, M.H., Gil, A.M., Silvestre, A.J.D., Neto, C.P., 2000. Composition of suberin extracted upon gradual alkaline methanolysis of Quercus suber L. cork. J. Agric. Food Chem. 48 (2), 383-391.

Marques, A.V., Pereira, H., Meier, D., Faix, O., 1994. Quantitative analysis of cork (Quercus suber L.) and milled cork lignin by FTIR spectroscopy, analytical pyrolysis, and total hydrolysis. Holzforschung 48, 43-50.

Olsson, A., Lindstrom, M., Iversen, T., 2007. Lipase-catalyzed synthesis of an epoxy-functionalized polyester from the suberin monomer cis-9,10-epoxy-18-hydroxyoctadecanoic acid. Biomacromolecules 8 (2), 757-760.

Paper and wood insights, 2006. http://www.forestindustries.fi (statistics for 2006).

Pereira, H., 1988. Chemical-composition and variability of cork from Quercus suber L. Wood Sci. Technol. 22 (3), 211-218.

Pinto, P.C., Evtuguin, D.V., Neto, C.P., 2005. Structure of hardwood glucuronoxylans: modifications and impact on pulp retention during wood kraft pulping. Carbohyd. Polym. 60, 489-497.

Selvendran, R.R., March, J.F., Ring, S.G., 1979. Determination of aldoses and uronic acid content of vegetable fiber. Anal. Biochem. 96 (2), 282-292.

Silva, S.P., Sabino, M.A., Fernandes, E.M., Correlo, V.M., Boesel, L.F., Reis, R.L., 2005. Cork: properties, capabilities and applications. Int. Mat. Rev. 50 (6), 345-365.

Sousa, A.F., Pinto, P., Silvestre, A.J.D., Neto, C.P., 2006. Triterpenic and other lipophilic components from industrial cork byproducts. J. Agric. Food Chem. 54 (18), 6888-6893.

Sousa, A.F., Pinto, P.C.R.O., Silvestre, A.J.D., Gandini, A., Neto, C.P., 2007. Novel biopolyesters from suberin monomers. In: Proceedings of the First International Conference on Biodegradable Polymers and Sustainable Composites, BIOPOL-2007, Alicante, Spain.

Sundberg, A., Sundberg, K., Lillandt, C., Holmbom, B., 1996. Determination of hemicelluloses and pectins in wood and pulp fibres by acid methanolysis and gas chromatography. Nord. Pulp Paper Res. J. 11 (4), 216-219.

Tegelaar, E.W., Hollman, G., Vandervegt, P., Deleeuw, J.W., Holloway, P.J., 1995. Chemical characterization of the periderm tissue of some angiosperm species-recognition of an insoluble, non-hydrolyzable, aliphatic biomacromolecule (Suberan). Org. Geochem. 23 (3), 239-251. 